\title{
Neonatal Hyperthyroidism in Mice Has Different Effects on Epidermal Growth Factor Levels in Submandibular Gland, Urine, and Blood
}

\author{
J. LAKSHMANAN, ${ }^{1}$ J. PERHEENTUPA, ${ }^{2}$ J. ALM, ${ }^{3}$ AND D. A. FISHER
}

Perinatal Research Laboratories, Harbor-UCLA Medical Center, Torrance, California 90509

\begin{abstract}
We examined long-term effects of neonatal hyperthryoidism in female mice by measuring the epidermal growth factor levels in the submandibular gland, urine, and serum at the age of $\mathbf{3 1}$ days. Hyperthyroxinemia was induced by thyroxine injections $(0.4 \mu \mathrm{g} / \mathrm{g} / \mathrm{day})$ on days $0_{-}$ 6 . Littermate controls received the alkaline saline vehicle. The treatment accelerated incisor eruption and eyelid opening. It also retarded growth. The elevation of plasma thyroxine concentration which normally occurs during wk 2 to reach a peak around day 15 was abolished. Submandibular gland epidermal growth factor levels on day 31 were markedly subnormal, indicating maturational delay. In contrast, epidermal growth factor levels were unaffected in urine and supranormal in serum. These differences in response suggest that the regulatory mechanisms governing epidermal growth factor levels in tissues and fluids may acquire thyroid hormone dependence at different stages. (Pediatr Res 20: 628-631, 1986)
\end{abstract}

\section{Abbreviations}

EGF, epidermal growth factor

SMG, submandibular salivary gland

T4, thyroxine

RIA, radioimmunoassay

EGF is present in adult mice in high concentrations in the SMG (1) and in low concentrations in various other tissues (2 3 ) and body fluids, including plasma (4) and urine $(5,6)$. But SMG EGF appears to make only a small contribution to plasma EGF (4) and none to urine EGF (7). The EGF-urea ratio is over 100 -fold higher in urine than in plasma (7). Hence, plasma EGF is presumably not a major source of urine EGF. Urine EGF concentration increases in the first $3 \mathrm{wk}$ of life, reaching about $80 \%$ of the adult levels at weaning (8), whereas SMG EGF levels begin to rise only thereafter and reach maximal levels several weeks later (9). Despite their different ontogenic profiles, both urine and SMG EGF levels in newborn mice respond to T4 treatment with a precocious increase during the 1 st and $2 \mathrm{nd} \mathrm{wk}$

Received September 26, 1985; accepted February 18, 1986.

Correspondence Dr. D. A. Fisher, Perinatal Research Laboratories, Harbor UCLA Medical Center, 1000 West Carson Street, Building A-17 Annex, Torrance, CA 90509 .

This work was supported by NIH Grants HD-04270 (DAF) and NS-17431a (JL).

Present address Center for Neurological Study, 11211 Sorrento Valley Rd., Suite H, San Diego, CA 92121.

${ }^{2}$ Present address Children's Hospital, S.F. 00290 Helsinki, Finland.

${ }^{3}$ Present address Department of Pediatrics, Karolinska Institute St. Goran's Children's Hospital, Stockholm, Sweden. of life, respectively (10). The magnitude of these responses depends on the timing and duration of the T4 treatment (10).

The present study examines the late effects of $\mathrm{T} 4$ treatment on days 0-6 on SMG, urine, and serum EGF levels. Such early T4 treatment abolishes the normal rise in serum T4 concentration which peaks around day 15 and is associated with a delay in the expected maturational increase in SMG EGF. In contrast, it increases serum EGF without affecting urinary EGF concentration. Thus thyroid hormone appears to regulate the EGF levels in SMG, urine, and serum independently.

\section{MATERIALS AND METHODS}

Animals. Multiparous pregnant Swiss-Webster mice from $\mathrm{Si}$ monsen Laboratories, Gilroy, CA were housed in plastic cages provided with sawdust bedding. They were given tap water and pelleted food ad libitum. Female pups born within a 16-h period were pooled and distributed randomly, eight pups per mother. Four pups in each litter were given injections of alkaline saline (vehicle), while the remaining four were given T4 injections $(0.4$ $\mu \mathrm{g} / \mathrm{g} /$ day) subcutaneously on days $0-6$. Pup weight and timing of tooth eruption and eyelid opening were recorded. On day 21 the pups were separated from their mothers and maintained four to a cage. From day 26 they were housed two to a cage. Only female pups were used to avoid the confounding effects of testosterone on EGF levels in males $(8,19)$. In a preliminary study, pups were raised in litter sizes of four to 12 from day 0 , resulting in two to 3-fold differences in body weight at 15 days of age. There were no differences in urine or SMG EGF ontogeny among these groups and, therefore, a third group of pups which controlled for differences in body weight was not considered necessary.

Groups of mice were killed by $\mathrm{CO}_{2}$ inhalation on days 7,15 , 21 , and 31 for measurements of T4. On day 7, trunk blood was collected; later blood samples were obtained from the inferior vena cava (4). For T4 determinations sera from two to four animals were pooled, and eight pools were used for each age group (11). At 31 days of age when serum and urine EGF levels have reached adult levels in female mice $(4,8), \mathrm{SMG}$, serum, and urine EGF were measured in individual control and T4treated mice ( 26 of each). In our hands serum and plasma EGF concentrations are equivalent (4).

Preparation of samples for RIA. Each SMG was homogenized in nine volumes of phosphate buffered saline, $\mathrm{pH} 7.2$, at $4^{\circ} \mathrm{C}$. The homogenate was centrifuged at $100,000 \times g$ for $30 \mathrm{~min}$ and the supernatant fluid was used for measurements of protein (12) and EGF $(4,13)$. Urine samples were diluted in RIA buffer, and aliquots were used for determination of urea (14) and EGF (6).

$E G F$ RIA. EGF was measured using a specific double-antibody, liquid phase, mouse EGF RIA (13). The sensitivity of the assay was $15-20$ pg EGF per assay tube. Intra- and interassay 
coefficients of variation were 5-10\%, and nonspecific binding was $<5 \%$. The EGF used for iodination and as standard was purified from SMG of adult Swiss-Webster mice (15).

Statistical analysis. All data were expressed as mean \pm SEM. Differences between mean values were evaluated by Student's $t$ test and, in multiple comparisons, by analysis of variance followed by the $t$ test as modified by Newman-Keul. A $p$ level of $<0.05$ was taken as the limit for a significant difference.

\section{RESULTS}

In mice treated with $\mathrm{T} 4$, incisor eruption and eyelid opening were advanced by 2 to 3 days compared with littermate controls treated with the vehicle (Fig. 1). T4 treatment caused significant slowing in body weight gain relative to littermate controls. No catch-up growth had appeared by the end of the observation period on day 31 (Fig. 2).

T4 treatment prevented the appearance of the normal ontogenic serum T4 peak which appeared on day 15 in the control animals. However, the T4 levels of T4-treated mice were similar to control levels on days 21 and 31 (Fig. 3).

As compared with the control mice on day 31, the T4-treated mice had EGF levels that were markedly lower in SMG and clearly higher in serum; urine EGF levels did not differ (Fig. 4).

\section{DISCUSSION}

The accelerated tooth eruption and eyelid opening observed in our T4-treated animals occurred during a period of time when T4 levels were lower than those of control animals since this therapy abolished the expected peak in serum T4 concentration which normally occurs during wk 2 of life (Figs. 1 and 3). Serum $\mathrm{T} 4$ levels were restored to normal by day 21 in the treated mice. This result is similar to that reported by Martin and Moberg in the neonatal rat (16). We did not study the mechanism of the
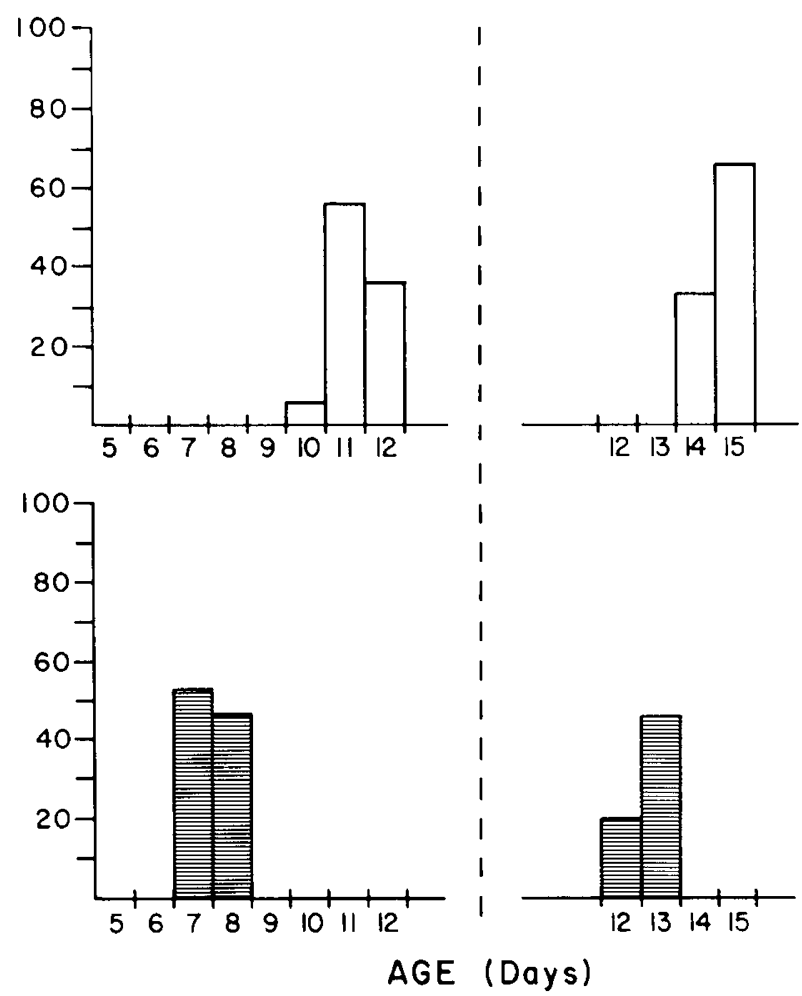

Fig. 1. Biologic responses to T4 treatment. Newborn mice were treated with vehicle (open columns) or $\mathrm{T} 4(0.4 \mu \mathrm{g} / \mathrm{g} / \mathrm{day}$ ) (striped columns) during days $0-6$. Time of tooth eruption (left panel) and eyelid opening (right panel) were recorded.

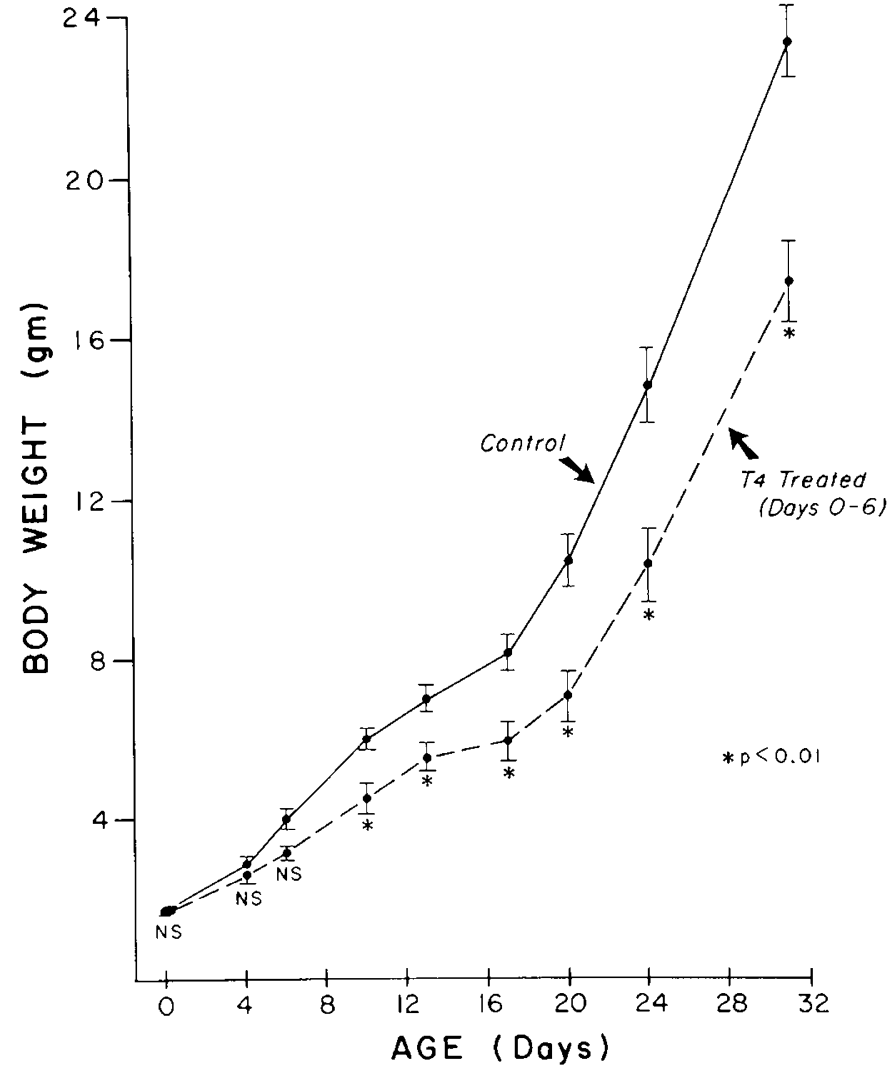

Fig. 2. Weight by age (mean $\pm \mathrm{SEM}$ ) in control (continuous line) and T4-treated (days 0-6, dashed line) pups. Significant intergroup differences are indicated.

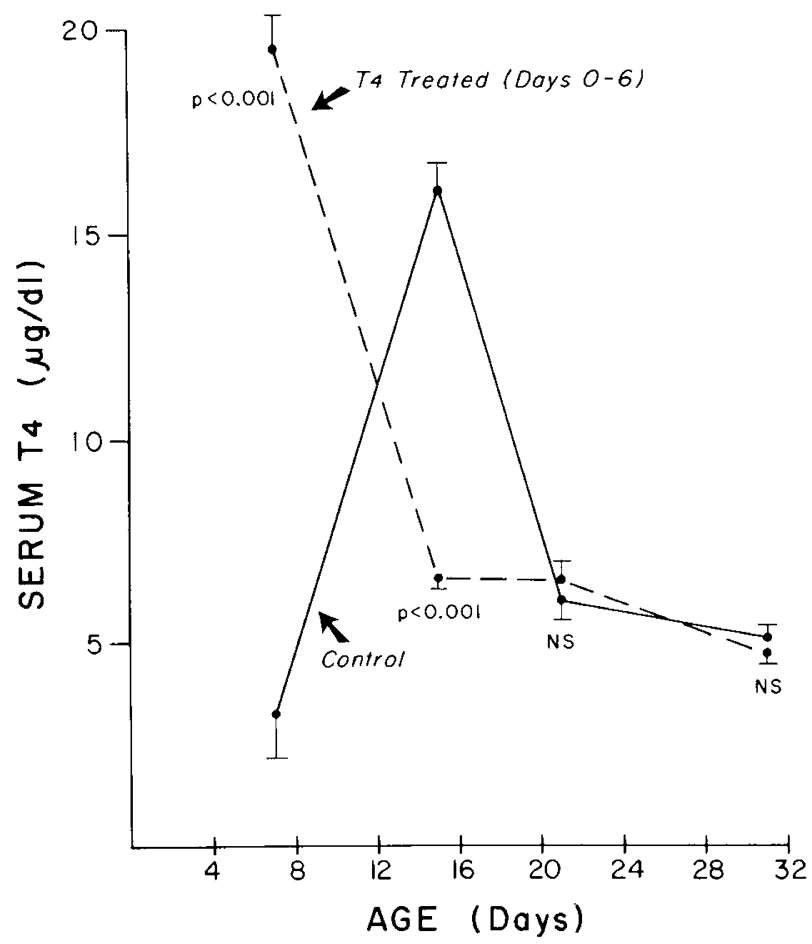

Fig. 3. Serum T4 concentrations (mean \pm SEM) by age in vehicletreated (continuous line) and T4-treated (dashed line) pups. Significant intergroup differences are indicated. 

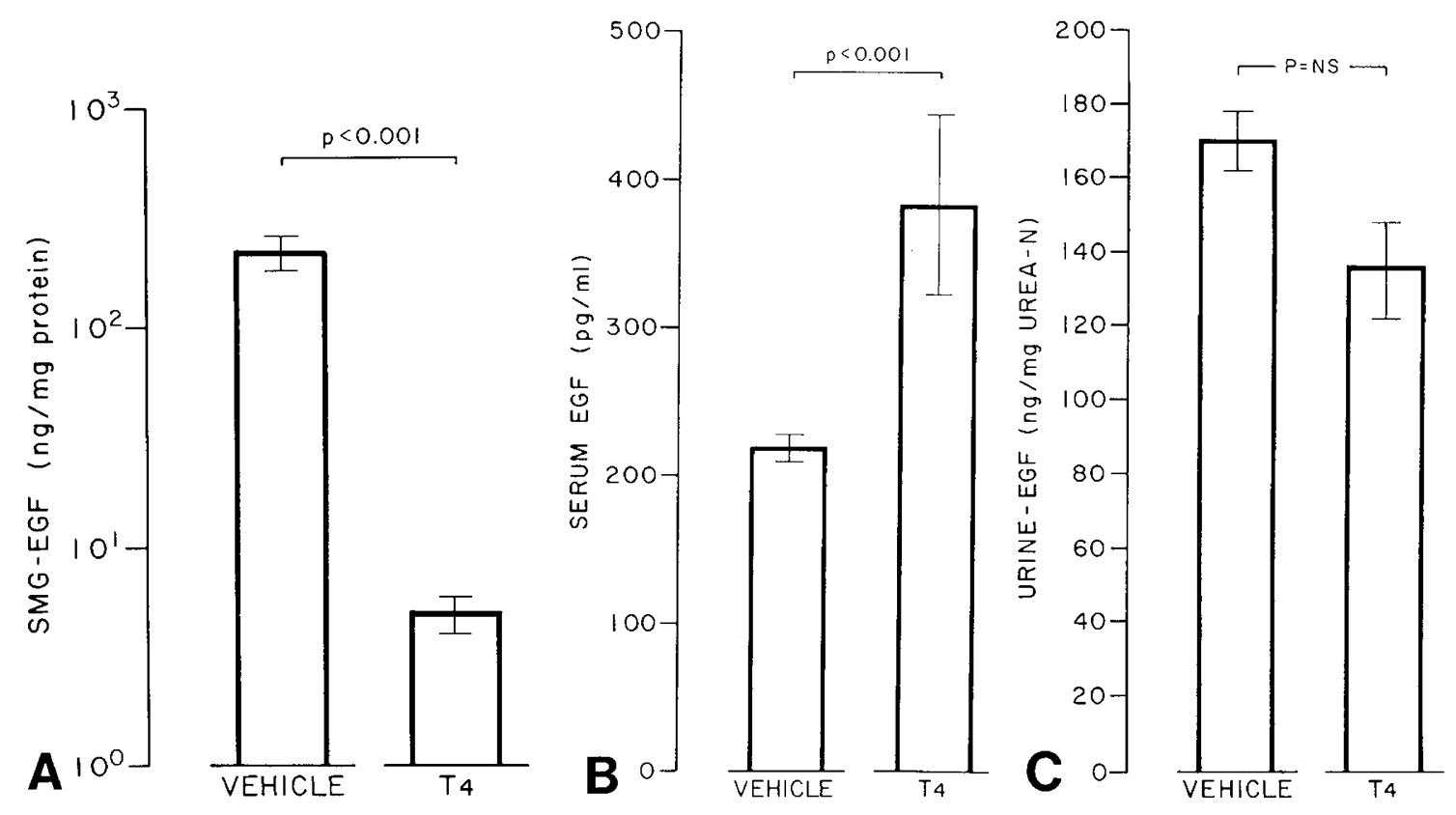

Fig. 4. EGF concentrations on day 31 in SMG (left panel, note log scale), serum (middle panel), and urine (right panel) in control mice and their T4-treated (days 0-6) littermates. $p$ values for intergroup differences are given above the columns.

altered serum $\mathrm{T} 4$ ontogeny. There is some evidence that the accelerating effect of T4 on incisor eruption and eyelid opening may be mediated by EGF. A similar acceleration is produced by exogenous EGF (1), and T4 treatment increases the EGF content of neonatal mouse ocular tissue (17). In the present study, involving a brief period of neonatal hyperthyroxinemia followed by a period of hypothyroxinemia, eyelid and tooth development were accelerated, indicating that the brief period of hyperthyroxinemia triggers these tissue responses which are then unaltered despite a subsequent period of hypothyroxinemia.

Body growth was impaired in the treated mice. This is not surprising and has been observed previously $(16,18)$. Both hyperthyroxinemia and the later hypothyroxinemia might be expected to retard growth. A surprising finding was the total absence of catch-up growth by day 31 , despite the fact that serum $\mathrm{T} 4$ levels were normal from day 21 . Other studies in rats have shown that this particular type of growth retardation is permanent and is associated with a state of relative hypothyroidism in older animals (18). Serum thyroid-stimulating hormone levels are reduced in such adult animals and the $\mathrm{T} 45^{\prime}$-monodeiodinase activity in pituitary tissue is increased, suggesting that the hypothyroxinemia may be conditioned by an alteration in pituitary feedback control of thyroid-stimulating hormone secretion (18). The T4 values in the present animals did not differ from control values at 21 and 31 days; however, serum thryoid-stimulating hormone levels were not measured. It is possible that other factors, including the elevated serum EGF, are contributing to the growth retardation.

Of the EGF responses studied in these developing mice, the SMG response was the most strikingly impaired. This is in marked contrast to adult mice, in which identical treatment enhances SMG EGF levels (19). Previously we reported that mouse SMG EGF synthesis only becomes $\mathrm{T} 4$ responsive during wk 2 of life (10). Our present observation suggests that the normal maturation of this system is critically dependent on thyroid activation during wk 2 . The mechanism of this dependence is not clear. Recently, a role for developing sympathetic nerve terminals was identified in the T4-mediated SMG EGF response during wk $2(20)$. It is not clear whether neonatal T4 treatment impairs the development of sympathetic innervation of the SMG or not. It would be of interest to determine whether the growth retardation and the diminished SMG EGF levels show later catch up or are permanently affected.

In urine, in contrast to the SMG, EGF levels were not altered. This is in keeping with our hypothesis (7) that urine EGF is not derived from the SMG. Both our study (7) and that of Olsen et al. (21) indicate that urine EGF may be derived from kidney tissue. We have shown (10) that urine EGF responsiveness to T4, in contrast to that of SMG EGF, appears during wk 1. Presumably, the pups treated with $\mathrm{T} 4$ on days $0-6$ had supranormal urine EGF levels by wk 2, but then showed no further increase or perhaps even a decrease, which allowed the controls to "catch up" with them by day 31 . The effect of hypothyroxinemia on urine EGF levels is unknown.

In contrast to SMG and urine EGF, serum EGF in the treated mice was increased on day 31 . This result is in keeping with our belief in the independence of serum EGF levels; this independence is relative with regard to an SMG source of EGF (4) and complete with regard to urine EGF (7). T4 treatment on days $0-$ 6 may have induced the elevated serum EGF levels on day 31 either directly or by way of the temporary hypothyroxinemia during wk 2.

The alterations in SMG and serum EGF levels in the T4treated animals suggest that the EGF developmental pattern or ontogenesis is programed by the levels of thyroid hormone in the early neonatal period. Hormonally induced "imprinting" also has been reported to follow neonatal androgen exposure in rats; in those studies the pattern of growth hormone secretion and of later body growth, as well as the pattern of hepatic steroid metabolism in the adulthood, was altered by early androgen exposure (22). The molecular basis for these early effects remains obscure.

\section{REFERENCES}

1. Cohen S 1962 Isolation of a mouse submaxillary gland protein accelerating incisor eruption and eyelid opening in newborn animals. $J$ Biol Chem 237:1555-1562

2. Byyny RL, Orth DA, Cohen S 1972 Radioimmunoassay of epidermal growth factor. Endocrinology 90:1261-1266

3. Frati L, Cenci G, Sbaraglia Teti DV, Cocelli I 1976 Levels of epidermal growth factor in mice tissues measured by a specific radioreceptor assay. Life Sci 18:905-912 
4. Perheentupa J, Lakshmanan J, Hoath SB, Beri U, Kim H, Macaso T, Fisher DA 1985 Epidermal growth factor measurements in mouse plasma: method, ontogeny and sex difference. Am J Physiol 248:E391-396

5. Hirata Y, Orth DN 1979 Concentrations of epidermal growth factor, nerve growth factor and submandibular gland renin in male and female mouse tissue and fluids. Endocrinology 105:1382-1387

6. Perheentupa J, Lakshmanan J, Fisher DA 1984 Epidermal growth factor in neonatal mouse urine: maturative effect of thyroxine. Pediatr Res 18:1080 1084

7. Perheentupa J, Lakshmanan J, Fisher DA 1985 Epidermal growth factor in mouse urine: non-blood origin, and increase by sialoadenectomy and $\mathrm{T} 4$ therapy. Acta Endocrinol (Copenh) 108:428-432

8. Perheentupa J, Lakshmanan J, Fisher DA 1985 Urine and kidney epidermal growth factor: ontogeny and sex difference in the mouse. Pediatr Res 19:428432

9. Walker P, Weichsel ME Jr, Eveleth D, Fisher DA 1982 Ontogenesis of nerve growth factor and epidermal growth factor in submaxillary glands and nerve growth factor in brains of immature mice. Correlation with ontogenesis of serum levels of thyroid hormones. Pediatr Res 16:520-524

10. Lakshmanan J, Perheentupa J, Macaso T, Fisher DA 1985 Acquisition of urine, kidney and submandibular gland epidermal growth factor responsiveness to thyroxine administration in neonatal mice. Acta Endocrinol (Copenh) 109:511-516

11. Chopra IJ 1972 A rapid radioimmunoassay for measurement of thyroxine in unextracted serum. J Clin Endocrinol Metab 34:938-944

12. Lowry OH, Rosebrough NN, Farr AL, Randall RJ 1951 Protein measurement with the Folin phenol reagent. J Biol Chem 193:263-275
13. Hoath SB, Lakshmanan J, Scott SM, Fisher DA 1983 Effects of thyroid hormone on epidermal growth factor concentration in neonatal mouse skin. Endocrinology 112:308-314

14. Henry RJ 1967 Clinical Chemistry: Principles and Technics. Hoeber Medical Division, Harper and Row, New York, pp 260-270

15. Savage CR, Jr, Cohen S 1972 Epidermal growth factor and a new derivative Rapid isolation procedures and biological and chemical characterization. $\mathrm{J}$ Biol Chem 147:7609-7611

16. Martin SM, Moberg GP 1981 Effects of early neonatal thyroxine treatment on development of the thyroid and adrenal axis in rats. Life Sci 19:1683-1688

17. Lakshmanan J, Perheentupa J, Hoath SB, Kim H, Grueters A, Odell C, Fisher DA 1985 Epidermal growth factor in mouse ocular tissue: effects of thyroxine and exogenous epidermal growth factor. Pediatr Res 19:315-319

18. Walker P Courtin F 1985 Transient neonatal hyperthyroidism results in hypothyroidism in the adult rat. Endocrinology 116:2246-2250

19. Perheentupa J, Lakshmanan J, Hoath SB, Fisher DA 1984 Hormonal modulation of mouse plasma concentration of epidermal growth factor. Acta Endocrinol (Copenh) 107:571-576

20. Lakshmanan J, Padbury J, Macaso T, Wang D, Fisher DA 1985 Involvement of sympathetic nervous system in submandibular gland nerve growth factor and epidermal growth factor responsiveness to thyroxine in neonatal mice. Clin Res 33:111A

21. Olsen PS, Nexo E, Poulsen SS, Hansen HF, Kirkegaard P 1984 Renal origin of rat urinary epidermal growth factor. Regul Peptides 10:37-45

22. Jansson JO, Ekberg S, Isaksson O, Mode A, Gustafson JA 1985 Imprinting of growth hormone secretion, body growth and hepatic steroid metabolism by neonatal testosterone. Endocrinology 117:1881-1889 